\title{
Evaluation Of Real-Time Delays For Networked Telerobotics
}

\author{
Al-Mouhamed, M.A. Toker, O. Iqbal, A. Islam, M.S.; Dept. of Comput. Sci. \& Eng., \\ King Fahd Univ. of Pet. \& Miner., Dhahran, Saudi Arabia; \\ Industrial Informatics, 2005. INDIN '05. 2005 3rd IEEE International \\ conference;Publication Date: 10-12 Aug. 2005; ISBN: 0-7803-9094-6
}

King Fahd University of Petroleum \& Minerals

http://www.kfupm.edu.sa

\section{Summary}

\begin{abstract}
A real-time telerobotic system consisting of client station (operator) and server station (slave arm) interconnected by a computer network has been implemented using a distributed component framework. To minimize overall delays a multithreaded execution is proposed for pipelining of information processing and real-time transmission. Thread engineering allowed pipelining stereo grabbing and live transfer of stereo video data. Different scenarios are statistically analyzed to relate the effect of thread manipulation to overall time delays. Analysis of telerobotic delays through three campus routes with different network loads is presented. A sampling rate of 120 $\mathrm{Hz}$ is achieved for force feedback and $50 \mathrm{~Hz}$ for operator commands when network load is below $80 \%$. Copying stereo images from cameras to memory is done in $24 \mathrm{~ms}$. Stereo video transfer operates at a rate of $17 \mathrm{fps}$. Total reference delays for force and stereo are $8 \mathrm{~ms}$ and $83 \mathrm{~ms}$, respectively. The environment interaction delay is $183 \mathrm{~ms}$ $(5.5 \mathrm{~Hz})$ when slave arm is operated at $10 \mathrm{~Hz}$. However, short instantaneous traffic irregularities may cause deviation and scattering from above reference rates.
\end{abstract}

For pre-prints please write †o:abstracts@kfupm.edu.sa

(c) Copyright: King Fahd University of Petroleum \& Minerals; http://www.kfupm.edu.sa 